\title{
Exploring the Association Between Social Media Addiction and Relationship Satisfaction: Psychological Distress as a Mediator
}

\author{
Begum Satici ${ }^{1}$ - Ahmet Rifat Kayis ${ }^{2}$ (D) Mark D. Griffiths ${ }^{3} \mathbb{D}$
}

Accepted: 13 September 2021

(c) The Author(s) 2021

\begin{abstract}
Social media use has become part of daily life for many people. Earlier research showed that problematic social media use is associated with psychological distress and relationship satisfaction. The aim of the present study was to examine the mediating role of psychological distress in the relationship between social media addiction (SMA) and romantic relationship satisfaction (RS). Participants comprised 334 undergraduates from four mid-sized universities in Turkey who completed an offline survey. The survey included the Relationship Assessment Scale, the Social Media Disorder Scale, and the Depression Anxiety and Stress Scale. According to the results, there were significant correlations between all variables. The results also indicated that depression, anxiety, and stress partially mediated the impact of SMA on RS. Moreover, utilizing the bootstrapping procedure the study found significant associations between SMA and RS via psychological distress. Consequently, reducing social media use may help couples deal with romantic relationship dissatisfaction, thereby mitigating their depression, anxiety, and stress.
\end{abstract}

Keywords Social media addiction · Problematic social media use · Online addiction · Psychological distress $\cdot$ Relationship satisfaction

Establishing social relationships is one of the basic needs of human beings (Heaney \& Israel, 2008). How this basic need is met can vary greatly. In particular, technological developments, such as computers, the Internet, and smartphones have created new ways

Mark D. Griffiths

mark.griffiths@ntu.ac.uk

Begum Satici

begum@artvin.edu.tr

Ahmet Rifat Kayis

arkayis@kastamonu.edu.tr

1 Department of Psychological Counselling, Artvin Coruh University, Artvin, Turkey

2 Department of Psychological Counselling, Kastamonu University, Kastamonu, Turkey

3 International Gaming Research Unit, Psychology Department, Nottingham Trent University, Nottingham, UK 
for people to communicate with each other. One of the most successful new means of communication is through social media. Social media involves many different communication (i.e., social networking) platforms. Among the most popular are platforms in Western countries are Facebook, Twitter, Instagram, and YouTube. These sites, which are accessed via the Internet, provide many opportunities for communication, such as voice and video messaging, photograph and video sharing, and creating profiles, through which individuals can introduce themselves and make connections with others.

The communication opportunities brought about by social networking sites (SNSs) allow for the development of social relationships (Fuchs, 2017; Hazar, 2011; Valentini, 2015). In addition, social media is used for a wider variety of purposes, including obtaining information, communicating, entertainment, playing games, and sharing photos, videos, and music (Griffiths, 2012). However, excessive use of social media including SNSs can cause negative effects (Griffiths, 2013; van den Eijnden et al., 2016). This phenomenon, which is sometimes referred as "social media addiction," is defined as the irrational and excessive use of social media at a level that negatively affects the daily life of the user (Griffiths, 2012). When social media use reaches the level of addiction, it can prevent the establishment of real, face-to-face social relationships (Glaser et al., 2018; Kuss \& Griffiths, 2017; Young, 2019). When general characteristics of social media addiction have been examined, it has been found that individuals tend to have restless thoughts concerning the urges and craving to be on social media, lose their self-control over their use of social media, spend excessive amounts of time staying on (or thinking about) social media which in turn lead to negative impacts on their relationships with their families and friends, and compromise their occupation and/or education (Andreassen et al., 2012; Griffiths et al., 2014). Therefore, examining social media addiction in terms of its effect on human relationships and mental health is an important pursuit.

\section{Theoretical Framework}

\section{Social Media Addiction and Relationship Satisfaction}

Research into the effects of social media addiction on romantic relationships has increased (Abbasi, 2019a; Demircioğlu \& Köse, 2018). The literature suggests that social media addiction negatively affects romantic relationships due to its tendency to create jealousy and suspicion and facilitate deception between married couples and committed partners (Abbasi, 2019b). Additionally, problematic social media use can hinder the development of face-to-face relationships (Glaser et al., 2018; Kuss \& Griffiths, 2017; Pollet et al., 2011; Young, 2019). Therefore, it is possible that some couples' relationships may become disrupted and that dissatisfaction may be experienced. In some cases, not only has social media use decreased the amount of relationships that individuals have in person, but it has also markedly impaired the quality of the time spent together. Therefore, it can be concluded that some couples may experience relationship dissatisfaction.

Similarly, social media addiction can result in low relationship satisfaction due to the existence of online alternative centers of attraction and investments of time and emotion outside the bilateral relationship in individuals aged between 18 and 73 years (Abbasi, 2019a). In addition, social media addiction has also been associated with physical and emotional infidelity, romantic separation, decline in the quality of romantic relationships, and relationship dissatisfaction (e.g., Abbasi, 2019a, b; Demircioğlu \& Köse, 2018; Valenzuela 
et al., 2014). Therefore, these aforementioned findings indicate that social media addiction negatively affects relationship satisfaction.

\section{Social Media Addiction and Psychological Distress}

One of the most important consequences of social media addiction is the mental health of individuals. When social media use reaches the level of addiction, it can create stress and negatively affect mental health rather than being a method of healthy coping. This occurs because social media addiction triggers social media fatigue and, as a result, individuals may experience anxiety and depression (Dhir et al., 2018). Social media users may use social media as a means of diversion in order to cope with stress (van den Eijnden et al., 2016). However, social media addicts give a lower priority to hobbies, daily routines, and close relationships (Tutgun-Ünal \& Deniz, 2015) which in turn lead to problems with daily functioning, completion of tasks, and relationship maintenance. This puts such individuals at risk for experiencing negative physical and psychological health.

In fact, some research has claimed that social media addiction triggers psychological distress factors, such as depression, anxiety (Woods \& Scott, 2016), and stress (Larcombe et al., 2016). In addition, a meta-analysis synthesizing the findings of 13 studies found that social media addiction may increase depression, anxiety, and stress levels (Keles et al., 2020). In both meta-analyses and cross-sectional studies, it has been found that social media addiction can increase psychological distress (e.g., Hou et al., 2019; Keles et al., 2020; Marino et al., 2018; Meena et al., 2015). In sum, these findings consistently associate social media addiction with psychological distress.

\section{Psychological Distress and Relationship Satisfaction}

Individuals experiencing psychological discomfort often have non-functional communication styles characterized by highly negative behaviors, such as criticism, complaining, hostility, defensiveness, and tendency to end relationships. They also experience problems actively listening to others (Fincham et al., 2018). In this respect, psychological distress prevents healthy communication in relationships, and a lack of healthy communication may cause conflicts that can embitter psychological distress between couples. Such a situation can continue in a cyclical manner that prevents relationship satisfaction. In romantic relationships, couples are supposed to fulfill their partners' emotional needs (Willard, 2011). When individuals have psychological problems due to social media addiction, they will ignore their partner's emotional needs because they would be trying to deal with their own problems, which, in turn, may lead to lower relationship satisfaction.

When psychological distress and romantic relationship satisfaction are examined, it can be seen that much psychological distress, such as major depression, panic disorder, social phobia, general anxiety disorder, post-traumatic stress disorder, and mood disorder, positively predict relationship dissatisfaction (Whisman, 1999). On the other hand, it can also be seen that individuals who are sensitive to negative affect in romantic relationships and who can successfully stop these emotions early on and cope with their feelings are satisfied with their relationships (Fincham et al., 2018).

Couples who have high levels of stress are reported to experience less satisfaction in their relationships (Bodenmann et al., 2007). In addition, it is known that depression negatively predicts relationship satisfaction (Cramer, 2004a, b; Tolpin et al., 2006). Therefore, it appears that psychological distress negatively affects relationship satisfaction. 


\section{The Present Study}

The prevalence of the use of the internet and Internet-related tools has consistently increased year on year (Roser et al., 2020). Even though the social media use is widespread and facilitates communication when it is used normally, it can negatively affect daily life when it is used excessively by some individuals. Literature reviews have shown that social media addiction has been mostly studied in East Asian countries like China, Japan, and South Korea (e.g., Bian \& Leung, 2015; Kwon et al., 2013; Tateno et al., 2019). In this respect, when the prevalence of social media use among Turkish people and the different cultural context of the present study are considered, the findings would arguably make important contributions to the current literature. Furthermore, the present study appears to be the first to examine the mediating role of psychological distress in the relationship between social media addiction and romantic relationship satisfaction.

Older aged adolescents and emerging adults are inextricably connected with technology in terms of their social media use and stand out as an important risk group in relation to problematic social media use (Griffiths et al., 2014). Many young adults closely follow technological developments and often adopt every innovation that arises into their lives without wasting time (Kuyucu, 2017). When such use becomes problematic, some individuals experience serious difficulty in maintaining their mental health. For example, cross-sectional studies among adolescents (Woods \& Scott, 2016) and young adults (Larcombe et al., 2016) have found that social media addiction can lead to stress, anxiety, and depression. Moreover, the establishment of close relationships as a young adult is an important stage of emotional and social development (Cashen \& Grotevant, 2019; Orenstein, \& Lewis, 2020). Romantic relationship satisfaction may be seen as an important indicator of young people's ability to engage in intimacy in a healthy manner (Orenstein \& Lewis, 2020). Therefore, the findings obtained as a result of examining the relationships between social media addiction, psychological distress, and romantic relationship satisfaction among young people will contribute to an understanding of the associations between the psychological and social variables regarding maintenance of their mental health and their success in establishing close relationships.

In previous studies of the variables examined in the present study, even though studies examining the three variables dichotomously have been conducted (e.g., Abbasi, 2019a, b; Bodenmann et al., 2007; Keles et al., 2020; Larcombe et al., 2016; Whisman, 1999), no research examining social media addiction, psychological distress (depression, anxiety and stress), and romantic relationship satisfaction together has been published. In particular, there is no study examining the role of psychological distress mediating between social media addiction and relationship satisfaction. In this respect, the results of the present study may also allow the findings of previous studies (which have been conducted with the aim of identifying the relationship between these variables) to be evaluated from a wider perspective.

Consequently, given the aforementioned theoretical explanations and the research findings, it has been demonstrated that social media addiction appears to induce both psychological distress and a low level of romantic relationship satisfaction (e.g., Demircioğlu \& Köse, 2018; Woods \& Scott, 2016). This is due to the deterioration of individuals' mental health that can arise as a result of social media addiction (Baker \& Algorta, 2016; Dhir et al., 2018), and in contrast to the advantages of developing relationships, it can lead to romantic relationship dissatisfaction (Abbasi, 2019b; Muise et al., 2009). Therefore, when the relationships between social media addiction, psychological distress, and romantic 
relationship satisfaction are evaluated simultaneously, psychological distress may represent a mediating variable between social media addiction and romantic relationship satisfaction. Consequently, it was hypothesized that psychological distress would mediate the association between social media addiction and relationship satisfaction.

\section{Method}

\section{Participants and Procedure}

The present cross-sectional study was carried out on a convenience sample of university students from three universities that are located in the west, middle, and east part of Turkey. A total of 350 surveys were originally distributed. Of these, 16 participants were removed because of incomplete data, yielding a final sample of 334 participants aged between 18 and 29 years $(M=20.71$ years, $S D=2.18)$. The participants comprised 214 females (64\%) and 120 males (36\%), of which 90 were freshmen, 87 were sophomores, 84 were junior students, and 73 were senior students. Participants reported that they were currently in a romantic relationship and reported having an average of 3.21 romantic relationships to date $(S D=2.21)$. Table 1 shows the detailed demographic characteristics of the participants. Written informed consent was obtained from the volunteer

Table 1 Participant characteristics $(N=334)$

\begin{tabular}{|c|c|c|}
\hline Variables & & $n(\%)$ or $($ Mean $\pm S D)$ \\
\hline \multirow[t]{2}{*}{ Gender } & Female & $214(64.1)$ \\
\hline & Male & $120(35.9)$ \\
\hline \multirow[t]{4}{*}{ Education } & Freshman & $90(26.9)$ \\
\hline & Sophomore & $87(26.0)$ \\
\hline & Junior & $84(25.1)$ \\
\hline & Senior & $73(21.9)$ \\
\hline \multirow[t]{4}{*}{ Majors } & Educational Sciences & $146(43.7)$ \\
\hline & Social Sciences & $97(29.0)$ \\
\hline & Sciences & $70(21.0)$ \\
\hline & Engineering Sciences & $21(6.3)$ \\
\hline \multirow[t]{3}{*}{ Income status } & Low & $34(10.2)$ \\
\hline & Moderate & $233(69.8)$ \\
\hline & High & $67(20.1)$ \\
\hline Age & & $20.71 \pm 2.18$ \\
\hline Time on social media (hours/day) & & $4.73 \pm 2.15$ \\
\hline Number of friends/followers & & $493.06 \pm 485.28$ \\
\hline Number of romantic relationships to date & & $3.21 \pm 2.21$ \\
\hline Independent variable & Social media addiction & $19.33 \pm 6.25$ \\
\hline \multirow[t]{3}{*}{ Mediators } & Depression & $6.12 \pm 5.24$ \\
\hline & Anxiety & $6.77 \pm 4.84$ \\
\hline & Stress & $8.09 \pm 5.13$ \\
\hline Dependent variable & Relationship satisfaction & $35.34 \pm 8.94$ \\
\hline
\end{tabular}


participants prior to participation in the study. Research participants were assured of the confidentiality of the collected data. Data collection was carried out through a "paperand-pencil" survey in the classroom environment. The surveys took less than 15 min to complete.

\section{Measures}

Relationship Assessment Scale (RAS) The RAS was designed to assess general relationship satisfaction (Hendrick, 1988). Items (e.g., "In general, how satisfied are you with your relationship?") utilize a seven-point Likert scale ranging from 1 (low) to 7 (high). The total score ranges from 7 to 49 . The higher the score, the higher the relationship satisfaction. Hendrick (1988) reported very good reliability. The RAS was adapted into Turkish by Curun (2001) with very good internal consistency. In the present study, the internal consistency of this scale was also good $(\alpha=0.80)$.

Social Media Disorder Scale (SMD) The SMD was designed to assess overall social media addiction, and the items were developed by adapting the DSM-5 criteria for Internet gaming disorder (van den Eijnden et al., 2016). This scale includes nine items (e.g., “... regularly found that you can't think of anything else but the moment that you will be able to use social media again?") to which participants indicate their level of agreement on a five-point Likert scale ranging from 0 (never) to 4 (always). The total score ranges from 0 to 36 . The higher the score, the higher the risk of social media addiction. The SMD was adapted to Turkish by Savci et al. (2018) and has very good internal consistency. In the present study, the internal consistency of this scale was also very good $(\alpha=0.88)$.

Depression Anxiety and Stress Scale (DASS-21) The DASS was designed to assess the level of psychological distress (Henry \& Crawford, 2005). The scale consists of 21 items that are rated on a four-point Likert scale from 0 (did not apply to me at all) to 3 (applied to me very much or most of the time) and comprises three sub-scales: depression (seven items; e.g., "I found it difficult to work up the initiative to do things"), anxiety (seven items; e.g., "I felt I was close to panic"), and stress (seven items; "I found myself getting agitated"). The scores range from 0 to 21 for each sub-scale. The DASS-21 subscales' scores were multiplied by two based on Lovibund and Lovibond's (1995) suggestion to the cut-offs (see Appendix 1). The DASS-21 was adapted to Turkish by Yilmaz et al. (2017) with good to very good internal consistencies. In the present study, the internal consistency of the subscales were all very good $(\alpha=0.89,0.82,0.85$, respectively).

\section{Statistical Analyses}

Pearson correlations, means, and standard deviations were examined as preliminary analyses for all study variables. To examine whether the association between social media addiction and relationship satisfaction was mediated by psychological distress, the mediation model was calculated using the PROCESS macro (model 4), developed by Hayes (2018). As recommended by Hayes (2018), all regression/path coefficients are in unstandardized form. A total of 10,000 bootstrap samples were generated and bias corrected $95 \%$ confidence intervals calculated. 


\section{Ethics}

Written informed consent was obtained from the volunteer participants prior to participation in the study. This research was approved by Artvin Coruh University Scientific Research and Ethical Review Board (REF: E.5375).

\section{Results}

\section{Descriptive Statistics}

Bivariate Pearson correlations among study variables were investigated (see Table 2). As expected, social media addiction was significantly and positively correlated with depression, anxiety, and stress. There was a significant negative correlation between social media addiction and relationship satisfaction.

Results indicated that 156 participants had no depressive symptoms (46.7\%), 54 participants had mild depressive symptoms (16.2\%), and the remainder had depressive symptoms (16.5\% moderate, $9.9 \%$ severe, and $10.8 \%$ extremely severe). Moreover, 101 participants had no anxiety symptoms (30.2\%), 30 participants had mild anxiety symptoms $(9.0 \%)$, and the remainder had anxiety symptoms (20.4\% moderate, $15.6 \%$ severe, and $24.9 \%$ extremely severe). Finally, 163 participants had no stress symptoms (48.8\%), 47 participants had mild depressive symptoms (14.1\%), and the remainder had stress symptoms (17.7\% moderate, $12.6 \%$ severe, and 6.9\% extremely severe) (see Appendix $1)$.

\section{Statistical Assumption Tests}

Prior to mediation analysis, statistical assumptions were evaluated. Skewness and kurtosis values ( $> \pm 2$; George \& Mallery, 2003) were checked for normality, and there were no violations (see Table 3). All reliability coefficients were above Nunnally and Bernstein's (1994) 0.70 criterion. Multicollinearity was checked with variance inflated factor (VIF), tolerance, and Durbin-Watson (DW) value. The results showed that VIF ranged from 1.47 to 2.09 and tolerance ranged from 0.48 to 0.87 . These findings also showed that there was no multiple linearity problem according to Field's (2013) recommendation. Also, the DW value was 1.82 indicating no significant correlations between the residuals.

Table 2 Correlations among study variables

\begin{tabular}{llllll}
\hline Variable & 1 & 2 & 3 & 4 & 5 \\
\hline 1. Social media addiction & - & & & & \\
2. Relationship satisfaction & $-.25^{* *}$ & - & & & \\
3. Depression & $.27^{* *}$ & $-.36^{* *}$ & - & & \\
4. Anxiety & $.30^{* *}$ & $-.36^{* *}$ & $.50^{* *}$ & - & \\
5. Stress & $.33^{* *}$ & $-.38^{* *}$ & $.60^{* *}$ & $.64^{* *}$ & - \\
\hline
\end{tabular}

*** $p<.001$ 
Table 3 Statistical information concerning study variables

\begin{tabular}{llllll}
\hline Variable & Skewness & Kurtosis & $\alpha$ & $\omega$ & $\lambda 6$ \\
\hline Social media addiction & -.637 & -.201 & .879 & .889 & .893 \\
Relationship satisfaction & .656 & .316 & .799 & .803 & .806 \\
Depression & .930 & .247 & .885 & .887 & .878 \\
Anxiety & .713 & -.069 & .820 & .823 & .820 \\
Stress & .432 & -.418 & .848 & .852 & .843 \\
\hline
\end{tabular}

$\alpha$ Cronbach's alpha; $\omega$ McDonald's omega; $\lambda 6$ Guttman's lambda- 6

\section{Mediation Analyses}

Applying PROCESS model 4, the analysis assessed whether psychological distress mediated the relationship between social media addiction and relationship satisfaction (see Table 4; Fig. 1). The results showed a significant total direct effect (path c; without mediator) of social media addiction on relationship satisfaction $(B=-0.36$, $t_{(334)}=-4.74, p=0.001,95 \% \mathrm{CI}=-0.51,-0.21$ ), significant direct effect (path $c$; with mediator) $\left(\mathrm{B}=-0.16, t_{(334)}=-2.11, p=0.03,95 \% \mathrm{CI}=-0.04,-0.01\right)$, and a significant indirect effect via psychological distress (total $\mathrm{B}=-0.20,95 \% \mathrm{CI}=-0.29,-0.12$ ).

The results also showed that the social media addiction was associated with higher depression scores (path $a_{1} ; \mathrm{B}=0.23, p=0.001$ ), anxiety scores (path $a_{2} ; \mathrm{B}=0.23$, $p=0.001$ ), and stress scores (path $a_{3} ; \mathrm{B}=0.27, p=0.001$ ), and these, in turn, were

Table 4 Path coefficients of the model

\begin{tabular}{|c|c|c|c|c|c|c|c|}
\hline \multirow[b]{2}{*}{ Model } & & \multirow[b]{2}{*}{ Estimate } & \multirow[b]{2}{*}{$S E$} & \multirow[b]{2}{*}{$t$} & \multirow[b]{2}{*}{$p$} & \multicolumn{2}{|l|}{$95 \% \mathrm{CI}$} \\
\hline & & & & & & Lower & Upper \\
\hline \multicolumn{8}{|c|}{ Model without mediator } \\
\hline Path $c$ & $\mathrm{SM} \rightarrow \mathrm{RS}$ & -.361 & .07 & -4.74 & $<.001$ & -.510 & -.211 \\
\hline \multicolumn{8}{|c|}{ Model with psychological distress as mediator } \\
\hline Path $a_{1}$ & $\mathrm{SM} \rightarrow \mathrm{DEP}$ & .227 & .04 & 5.13 & $<.001$ & .140 & .315 \\
\hline Path $a_{2}$ & $\mathrm{SM} \rightarrow \mathrm{ANX}$ & .232 & .04 & 5.71 & $<.001$ & .152 & .312 \\
\hline Path $a_{3}$ & $\mathrm{SM} \rightarrow \mathrm{STR}$ & .274 & .04 & 6.43 & $<.001$ & .190 & .357 \\
\hline Path $b_{1}$ & $\mathrm{DEP} \rightarrow \mathrm{RS}$ & -.280 & .10 & -2.61 & .009 & -.491 & -.068 \\
\hline Path $b_{2}$ & $\mathrm{ANX} \rightarrow \mathrm{RS}$ & -.281 & .12 & -2.32 & .021 & -.518 & -.043 \\
\hline Path $b_{3}$ & $\mathrm{STR} \rightarrow \mathrm{RS}$ & -.263 & .12 & -2.12 & .034 & -.507 & -.019 \\
\hline Path $c^{\prime}$ & $\mathrm{SM} \rightarrow \mathrm{RS}$ & -.160 & .07 & -2.11 & .035 & -.308 & -.011 \\
\hline \multirow[t]{4}{*}{$a^{*} b$} & Total indirect effect & -.200 & .04 & & & -.293 & -.121 \\
\hline & Indirect effect of DEP & -.064 & .03 & & & -.128 & -.014 \\
\hline & Indirect effect of ANX & -.065 & .03 & & & -.139 & -.007 \\
\hline & Indirect effect of STR & -.072 & .04 & & & -.156 & -.009 \\
\hline
\end{tabular}

$S M$ social media addiction (independent variable), $R S$ relationship satisfaction (dependent variable), $D E P$ depression (mediator), $A N X$ anxiety (mediator), STR stress (mediator) 


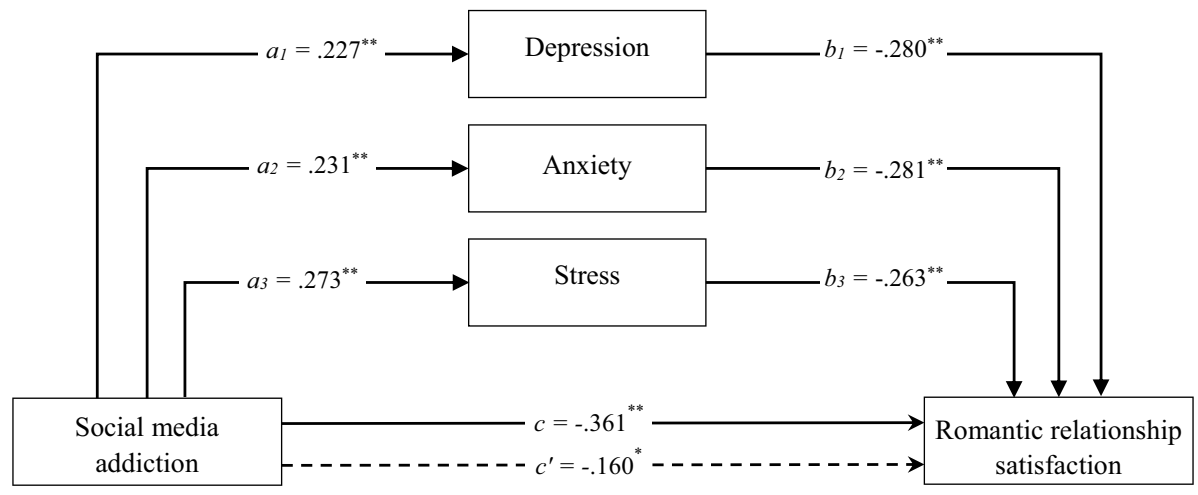

Fig. 1 The mediation model. ${ }^{*} p<.05 .{ }^{* *} p<.001$

negatively associated with relationship satisfaction (path $b_{1}, b_{2}, b_{3} ; \mathrm{B}=-0.28$, $\mathrm{B}=-0.28, \mathrm{~B}=-0.26$, all $p$ values $<0.05$, respectively).

\section{Discussion}

In contemporary society, rapidly developing technology has entered human life, but some individuals may have difficulty in adapting to the innovations brought by such technology. Consequently, some individuals may experience psychological and social problems. Social media use, which has markedly increased in the past decade, can cause psychological distress (e.g., Keles et al., 2020; Marino et al., 2018) and the deterioration of interpersonal relationships (e.g., Glaser et al., 2018; Kuss \& Griffiths, 2017; Young, 2019) among a minority of individuals. In this context, the main purpose of the present study was to evaluate the mediating role of psychological distress in the relationship between social media addiction and romantic relationship satisfaction.

According to the findings, a high level of social media addiction leads to a decrease in relationship satisfaction. Consequently, the first hypothesis was confirmed. A recent study conducted by Abbasi (2019b) found that social media addiction was negatively associated with romantic relationship commitment. In another recent study, it was emphasized that social media addiction results in deception between couples through social media and may lead to the deterioration of relationships as a consequence (Abbasi, 2019a). In addition, social media addiction not only leads to physical and emotional deception but also appears to negatively impact on the quality of romantic relationships (Demircioğlu \& Köse 2018; Valenzuela et al., 2014). Therefore, the findings obtained in the present study are in line with the findings of previous research.

In the study here, the findings showed that a high level of social media addiction appears to result in psychological distress. Dhir et al. (2018) argued that social media addiction triggers social media fatigue, leading to anxiety and depression. Similarly, social media addiction has been found to be associated with depression, anxiety (Woods \& Scott, 2016) and stress (Larcombe et al., 2016). In addition, a recent meta-analysis also concluded that social media addiction is closely and positively associated depression, anxiety and stress 
(Marino et al., 2018). Therefore, the findings of the present study are consistent with previous research.

Thirdly, the findings indicate that individuals who experience psychological distress have a low level of satisfaction in their romantic relationships. Whisman (1999) found that psychological distress positively predicted relationship dissatisfaction. It has also been suggested that couples with high levels of stress experience dissatisfaction in their romantic relationships (Bodenmann et al., 2007). In addition, there have also been a number of studies which indicate that the relationship satisfaction of individuals with high levels of depression is low (Cramer, 2004a, b; Tolpin et al., 2006). In this respect, the findings obtained from the present study are similar to the findings of the previous studies.

Within the scope of this study, it was hypothesized that psychological distress would mediate between social media addiction and relationship satisfaction. In this sense, the study showed that social media addiction predicted romantic relationship satisfaction, partially mediated by psychological distress. Consequently, the fourth hypothesis of the research was also confirmed. No previous studies have examined the effect of psychological distress in the relationship between social media addiction and relationship satisfaction. However, there are research findings which provide evidence that social media addiction predicts both psychological distress (e.g., Larcombe et al., 2016; Woods \& Scott, 2016) and relationship dissatisfaction (e.g., Demircioğlu \& Köse, 2018; Valenzuela et al., 2014) and that psychological distress predicts relationship dissatisfaction (e.g., Bodenmann et al., 2007; Whisman, 1999). Due to the consideration of a variable's mediating conditions (Barron \& Kenny, 1986), it may be asserted that the findings of the previous studies in the literature and the findings of this research are consistent. Furthermore, it has been demonstrated that technological addiction, such as Internet addiction and smartphone addiction, is associated with psychological distress (McNicol \& Thorsteinsson, 2017; Samaha \& Hawi, 2016; Young \& Rogers, 1998). Psychological distress may also predict variables such as closeness in relationships (Manne et al., 2010), dating violence (Cascardi, 2016), and social support (Robitaille et al., 2012) which are based on interpersonal relationships. It is therefore suggested that there is similarity between these findings and the findings of the present study. Consequently, it may be that the results of the studies conducted previously support the findings of this the present research indirectly, if not directly.

In the study here, the mediating role of psychological distress in the relationship between social media addiction and romantic relationship satisfaction was investigated. However, there could be some other variables that can mediate the relationship between social media addiction and romantic relationship satisfaction. For instance, romantic relationships are considered interpersonal (Knap et al., 2002); therefore, it can be assumed that interpersonal relationships and communication skills can be seen as potential mediators of the relationship between social media addiction and romantic relationship satisfaction. Additionally, given that psychological problems are the indicators of poor mental health (American Psychiatric Association, 2013), it can be assumed that variables (i.e., other indicators of poor mental health such as burnout, somatization, and hostility) would mediate the relationship between social media addiction and romantic relationship satisfaction. Therefore, future studies should investigate such relationships more closely.

When the role of social media addiction in the development of psychological distress is considered, it is necessary for social media addiction to be included in the process of 
forming the content of the intervention programs that aim to treat psychological distress. As such, it is interesting that an intervention program aimed at decreasing the level of social media addiction was also found to have a beneficial impact on individuals' mental health (Hou et al., 2019). Likewise, the treatment of couples' social media usage habits in family and couple therapies may be effective in terms of the efficacy of the therapy, since social media addiction decreases satisfaction in romantic relationships. Moreover, given the mediation relationships in the present research, the results may provide a more holistic viewpoint for mental health professionals which consider all of the three variables (social media addiction, psychological distress, and romantic relationship satisfaction) rather than a focus on only one. In this context, the following suggestions are made: to prevent social media addiction, effective Internet use skills can be taught to couples. In addition, awareness-raising skills such as yoga and meditation could be provided to individuals to protect them from social media addiction and psychological distress.

In terms of the study's participatory group, it is significant that social media addiction (Kittinger et al., 2012; Koc \& Gulyagci, 2013), psychological distress (Canby et al., 2015; Larcombe et al., 2016), and relationship satisfaction problems (Bruner et al., 2015; Roberts \& David, 2016) are frequently experienced by university students. Consequently, the findings of the present study may be of particular help to specialists who work in the psychological counseling centers of universities. Within this framework, meetings, conferences, and psycho-educational group activities could be carried out to improve relationship building skills, as well as activities preventing social media addiction and psychological distress.

The present study has some limitations. Firstly, the data comprised self-report scales, which may decrease internal reliability, a limitation which may be prevented through the use of different methods of data collection. Secondly, the generalizability of the findings is limited since the sample was based on convenience sampling. Thirdly, the research design was cross-sectional. This may make it difficult to explain the cause-effect relationship of variables in the study, and therefore, experimental and longitudinal studies are recommended in future research which should examine the relationship between these variables. Finally, only the mediating role of psychological distress was examined in the research. Other possible mediating variables were not examined.

\section{Conclusion}

In the present research, the mediation of psychological distress in the relationship between social media addiction and romantic relationship satisfaction was empirically tested. Results showed that social media addiction predicted the partial mediation of depression, anxiety, and stress on romantic relationship satisfaction. In other words, social media addiction apparently increased individuals' depression, anxiety, and stress levels, and this situation decreased the level of satisfaction in individual's romantic relationships. In the present study, psychological and social variables were examined simultaneously. Overall, this study suggests that social media addiction may have a meaningful but negative impact on romantic relationship satisfaction via depression, anxiety, and stress. 


\section{Appendix 1}

Depression, Anxiety and Stress Scale: Cut-Off Criteria and Distribution of Participants

\begin{tabular}{|c|c|c|c|}
\hline & Depression & Anxiety & Stress \\
\hline \multicolumn{4}{|l|}{ Cut-off criteria } \\
\hline Normal & $0-9$ & $0-7$ & $0-14$ \\
\hline Mild & $10-13$ & $8-9$ & $15-18$ \\
\hline Moderate & $14-20$ & $10-14$ & $19-25$ \\
\hline Severe & $21-27$ & $15-19$ & $26-33$ \\
\hline Extremely severe & $28+$ & $20+$ & $34+$ \\
\hline \multicolumn{4}{|l|}{ Distribution $^{*}$} \\
\hline Normal & $156(46.7 \%)$ & $101(30.2 \%)$ & $163(48.8 \%)$ \\
\hline Mild & $54(16.2 \%)$ & $30(9.0 \%)$ & $47(14.1 \%)$ \\
\hline Moderate & $55(16.5 \%)$ & $68(20.4 \%)$ & $59(17.7 \%)$ \\
\hline Severe & $33(9.9 \%)$ & $52(15.6 \%)$ & $42(12.6 \%)$ \\
\hline Extremely severe & $36(10.8)$ & $83(24.9 \%)$ & $23(6.9 \%)$ \\
\hline
\end{tabular}

${ }^{*} n(\%)$

Scores on the DASS-21 are multiplied by 2 to calculate the final score

\section{Declarations}

Ethics Approval All procedures performed in this study involving human participants were in accordance with the ethical standards of University's Research Ethics Board and with the 1975 Helsinki Declaration.

Consent to Participate Informed consent was obtained from all participants.

Conflict of Interest The authors declare no competing interests.

Open Access This article is licensed under a Creative Commons Attribution 4.0 International License, which permits use, sharing, adaptation, distribution and reproduction in any medium or format, as long as you give appropriate credit to the original author(s) and the source, provide a link to the Creative Commons licence, and indicate if changes were made. The images or other third party material in this article are included in the article's Creative Commons licence, unless indicated otherwise in a credit line to the material. If material is not included in the article's Creative Commons licence and your intended use is not permitted by statutory regulation or exceeds the permitted use, you will need to obtain permission directly from the copyright holder. To view a copy of this licence, visit http://creativecommons.org/licenses/by/4.0/.

\section{References}

Abbasi, I. S. (2019a). Social media addiction in romantic relationships: Does user's age influence vulnerability to social media infidelity? Personality and Individual Differences, 139, 277-280. https:// doi.org/10.1016/j.paid.2018.10.038

Abbasi, I. S. (2019b). Social media and committed relationships: What factors make our romantic relationship vulnerable? Social Science Computer Review, 37(3), 425-435. https://doi.org/10.1177/ 0894439318770609

American Psychiatric Association. (2013). Diagnostic and statistical manual of mental disorders (5th ed.). Author. https://doi.org/10.1176/appi.books.9780890425596 
Andreassen, C. S., Torsheim, T., Brunborg, G. S., \& Pallesen, S. (2012). Development of a facebook addiction scale. Psychological Reports, 110(2), 501-517. https://doi.org/10.2466/02.09.18.PR0. 110.2.501-517

Baker, D. A., \& Algorta, G. P. (2016). The relationship between online social networking and depression: A systematic review of quantitative studies. CyberPsychology, Behavior, and Social Networking, 19(11), 638-648. https://doi.org/10.1089/cyber.2016.0206

Barron, R. M., \& Kenny, D. A. (1986). The moderator-mediator variable distinction in social psychological research: Conceptual, strategic, and statistical considerations. Journal of Personality and Social Psychology, 51(6), 1173-1182. https://doi.org/10.1037/0022-3514.51.6.1173

Bian, M., \& Leung, L. (2015). Linking loneliness, shyness, smartphone addiction symptoms, and patterns of smartphone use to social capital. Social Science Computer Review, 33(1), 61-79. https:// doi.org/10.1177/0894439314528779

Bodenmann, G., Ledermann, T., \& Bradbury, T. N. (2007). Stress, sex, and satisfaction in marriage. Personal Relationships, 14(4), 551-569. https://doi.org/10.1111/j.1475-6811.2007.00171.x

Bruner, M. R., Kuryluk, A. D., \& Whitton, S. W. (2015). Attention-deficit/hyperactivity disorder symptom levels and romantic relationship quality in college students. Journal of American College Health, 63(2), 98-108. https://doi.org/10.1080/07448481.2014.975717

Canby, N. K., Cameron, I. M., Calhoun, A. T., \& Buchanan, G. M. (2015). A brief mindfulness intervention for healthy college students and its effects on psychological distress, self-control, meta-mood, and subjective vitality. Mindfulness, 6(5), 1071-1081. https://doi.org/10.1007/s12671-014-0356-5

Cascardi, M. (2016). From violence in the home to physical dating violence victimization: The mediating role of psychological distress in a prospective study of female adolescents. Journal of Youth and Adolescence, 45(4), 777-792. https://doi.org/10.1007/s10964-016-0434-1

Cashen, K. K., \& Grotevant, H. D. (2019). Relational competence in emerging adult adoptees: Conceptualizing competence in close relationships. Journal of Adult Development. Advanced online publication. https://doi.org/10.1007/s10804-019-09328-x

Cramer, D. (2004a). Emotional support, conflict, depression, and relationship satisfaction in a romantic partner. Journal of Psychology, 138(6), 532-542. https://doi.org/10.3200/JRLP.138.6.532-542

Cramer, D. (2004b). Satisfaction with a romantic relationship, depression, support and conflict. Psychology and Psychotherapy: Theory, Research and Practice, 77(4), 449-461. https://doi.org/10.1348/14760 83042555389

Curun, F. (2001). The effects of sexism and sex role orientation on relationship satisfaction. [Unpublished Master's thesis, Middle East Technical University], Ankara, Turkey.

Demircioğlu, Z. I., \& Köse, A. G. (2018). Effects of attachment styles, dark triad, rejection sensitivity, and relationship satisfaction on social media addiction: A mediated model. Current Psychology. Advanced online publication. https://doi.org/10.1007/s12144-018-9956-X

Dhir, A., Yossatorn, Y., Kaur, P., \& Chen, S. (2018). Online social media fatigue and psychological wellbeing - A study of compulsive use, fear of missing out, fatigue, anxiety and depression. International Journal of Information Management, 40, 141-152. https://doi.org/10.1016/j.ijinfomgt.2018.01.012

Field, A. (2013). Discovering statistics using IBM SPSS statistics (4th ed.). Sage.

Fincham, F. D., Rogge, R., \& Beach, S. R. H. (2018). Relationship satisfaction. In A. Vangelisti \& D. Perlman (Eds.), The Cambridge handbook of personal relationships (pp. 579-594). Cambridge University Press. https://doi.org/10.1017/CBO9780511606632.032

Fuchs, C. (2017). Social media: A critical introduction. Sage.

George, D., \& Mallery, P. (2003). SPSS for windows step by step: A simple guide and reference. Allyn and Bacon.

Glaser, P., Liu, J. H., Hakim, M. A., Vilar, R., \& Zhang, R. (2018). Is social media use for networking positive or negative? Offline social capital and internet addiction as mediators for the relationship between social media use and mental health. New Zealand Journal of Psychology, 47(3), 12-18.

Griffiths, M. D. (2012). Facebook addiction: Concerns, criticism, and recommendations: A response to Andreassen and colleagues. Psychological Reports, 110, 518-520. https://doi.org/10.2466/01.07.18. PR0.110.2.518-520

Griffiths, M. D. (2013). Social networking addiction: Emerging themes and issues. Journal of Addiction Research \& Therapy, 4(5), e118. https://doi.org/10.4172/2155-6105.1000e118

Griffiths, M. D., Kuss, D. J., \& Demetrovics, Z. (2014). Social networking addiction: An overview of preliminary findings. In K. Rosenberg \& L. Feder (Eds.), Behavioral Addictions: Criteria, Evidence and Treatment (pp. 119-141). Elsevier.

Hayes, A. F. (2018). Introduction to mediation, moderation, and conditional process analysis: A regressionbased approach. Guilford Publications. 
Hazar, M. (2011). Sosyal medya bağımlılı̆̆ı: Bir alan çalışması. Illetişim, Kuram Ve Araştırma Dergisi, 32 , $151-175$.

Heaney, C. A., \& Israel, B. A. (2008). Social networks and social support. In K. Glanz, B. K. Rimer, \& K. Viswanath (Eds.), Health behavior and health education: Theory, research, and practice (pp. 189210). Wiley.

Hendrick, S. S. (1988). A generic measure of relationship satisfaction. Journal of Marriage and the Family, 50, 93-98. https://doi.org/10.2307/352430

Henry, J. D., \& Crawford, J. R. (2005). The short-form version of the depression anxiety stress scales (DASS-21): Construct validity and normative data in a large non-clinical sample. British Journal of Clinical Psychology, 44(2), 227-239. https://doi.org/10.1348/014466505X29657

Hou, Y., Xiong, D., Jiang, T., Song, L., \& Wang, Q. (2019). Social media addiction: Its impact, mediation, and intervention. Cyberpsychology: Journal of Psychosocial Research on Cyberspace, 13(1), 4. https://doi.org/10.5817/CP2019-1-4

Keles, B., McCrae, N., \& Grealish, A. (2020). A systematic review: The influence of social media on depression, anxiety and psychological distress in adolescents. International Journal of Adolescence and Youth, 25(1), 79-93. https://doi.org/10.1080/02673843.2019.1590851

Kittinger, R., Correia, C. J., \& Irons, J. G. (2012). Relationship between Facebook use and problematic internet use among college students. Cyberpsychology, Behavior, and Social Networking, 15(6), 324327. https://doi.org/10.1089/cyber.2010.0410

Knap, M. L., Daly, J. A., Albada, K. F., \& Miller, G. R. (2002). Handbook of interpersonal communication. Sage.

Koc, M., \& Gulyagci, S. (2013). Facebook addiction among Turkish college students: The role of psychological health, demographic, and usage characteristics. Cyberpsychology, Behavior, and Social Networking, 16(4), 279-284. https://doi.org/10.1089/cyber.2012.0249

Kuss, D., \& Griffiths, M. (2017). Social networking sites and addiction: Ten lessons learned. International Journal of Environmental Research and Public Health, 14(3), 311. https://doi.org/10.3390/ijerph1403 0311

Kuyucu, M. (2017). Y kuşağı ve teknoloji: Y kuşağının iletişim teknolojilerini kullanım alışkanlıkları. Gümüşhane Üniversitesi Iletişim Fakültesi Elektronik Dergisi, 5(2), 845-872. https://doi.org/10.19145/ e-gifder.285714

Kwon, M., Kim, D. J., Cho, H., \& Yang, S. (2013). The smartphone addiction scale: Development and validation of a short version for adolescents. PLOS ONE, 8(12), e83558. https://doi.org/10.1371/journal. pone. 0083558

Larcombe, W., Finch, S., Sore, R., Murray, C. M., Kentish, S., Mulder, R. A., ... \& Williams, D. A. (2016). Prevalence and socio-demographic correlates of psychological distress among students at an Australian university. Studies in Higher Education, 41(6), 1074-1091.https://doi.org/10.1080/03075079.2014. 966072

Lovibund, S., \& Lovibund, P. (1995). Manual for the depression anxiety stress scales. Psychology Foundation.

Maier, C., Laumer, S., Weinert, C., \& Weitzel, T. (2015). The effects of technostress and switching stress on discontinued use of social networking services: A study of Facebook use. Information Systems Journal, 25(3), 275-308. https://doi.org/10.1111/isj.12068

Manne, S., Badr, H., Zaider, T., Nelson, C., \& Kissane, D. (2010). Cancer-related communication, relationship intimacy, and psychological distress among couples coping with localized prostate cancer. Journal of Cancer Survivorship, 4(1), 74-85. https://doi.org/10.1007/s11764-009-0109-y

Marino, C., Gini, G., Vieno, A., \& Spada, M. M. (2018). The associations between problematic Facebook use, psychological distress and well-being among adolescents and young adults: A systematic review and meta-analysis. Journal of Affective Disorders, 226, 274-281. https://doi.org/10.1016/j.jad.2017.10. 007

McNicol, M. L., \& Thorsteinsson, E. B. (2017). Internet addiction, psychological distress, and coping responses among adolescents and adults. Cyberpsychology, Behavior, and Social Networking, 20(5), 296-304. https://doi.org/10.1089/cyber.2016.0669

Meena, P. S., Soni, R., Jain, M., \& Paliwal, S. (2015). Social networking sites addiction and associated psychological problems among young adults: A study from North India. Sri Lanka Journal of Psychiatry, 6(1), 14-16. https://doi.org/10.4038/sljpsyc.v6i1.8055

Muise, A., Christofides, E., \& Desmarais, S. (2009). More information than you ever wanted: Does Facebook bring out the green-eyed monster of jealousy? CyberPsychology \& Behavior, 12(4), 441-444. https://doi.org/10.1089/cpb.2008.0263

Nunnally, J. C., \& Bernstein, I. H. (1994). Psychometric theory (3rd ed.). McGraw-Hill. 
Orenstein, G. A., \& Lewis, L. (2020). Eriksons stages of psychosocial development. In StatPearls [Internet]. StatPearls Publishing. Retrived May 12, 2020, from https://www.ncbi.nlm.nih.gov/books/NBK55 $6096 /$

Pollet, T. V., Roberts, S. G., \& Dunbar, R. I. (2011). Use of social network sites and instant messaging does not lead to increased offline social network size, or to emotionally closer relationships with offline network members. Cyberpsychology, Behavior, and Social Networking, 14(4), 253-258. https://doi.org/ 10.1089/cyber.2010.0161

Roberts, J. A., \& David, M. E. (2016). My life has become a major distraction from my cell phone: Partner phubbing and relationship satisfaction among romantic partners. Computers in Human Behavior, 54, 134-141. https://doi.org/10.1016/j.chb.2015.07.058

Robitaille, A., Orpana, H., \& McIntosh, C. N. (2012). Reciprocal relationship between social support and psychological distress among a national sample of older adults: An autoregressive cross-lagged model. Canadian Journal on Aging/la Revue Canadienne Du Vieillissement, 31(1), 13-24. https://doi.org/10. $1017 / \mathrm{S} 0714980811000560$

Roser, M., Ritchie, H., \& Ortiz-Ospina, E. (2020). Internet. Retrieved May 12, 2020, from https://ourwo rldindata.org/internet

Samaha, M., \& Hawi, N. S. (2016). Relationships among smartphone addiction, stress, academic performance, and satisfaction with life. Computers in Human Behavior, 57, 321-325. https://doi.org/10. 1016/j.chb.2015.12.045

Savci, M., Ercengiz, M., \& Aysan, F. (2018). Turkish adaptation of the social media disorder scale in adolescents. Archives of Neuropsychiatry, 55(3), 248-255. https://doi.org/10.29399/npa.19285

Tateno, M., Kim, D. J., Teo, A. R., Skokauskas, N., Guerrero, A. P., \& Kato, T. A. (2019). Smartphone addiction in Japanese college students: usefulness of the Japanese version of the smartphone addiction scale as a screening tool for a new form of internet addiction. Psychiatry Investigation, 16(2), 115-120. https://doi.org/10.30773/pi.2018.12.25.2

Tolpin, L. H., Cohen, L. H., Gunthert, K. C., \& Farrehi, A. (2006). Unique effects of depressive symptoms and relationship satisfaction on exposure and reactivity to daily romantic relationship stress. Journal of Social and Clinical Psychology, 25(5), 565-583. https://doi.org/10.1521/jscp.2006.25.5.565

Tutgun-Ünal, A., \& Deniz, L. (2015). Development of the social media addiction scale. Online Academic Journal of Information Technology, 6(21), 51-70. https://doi.org/10.5824/1309-1581.2015.4.004.x

Valentini, C. (2015). Is using social media "good" for the public relations profession? A Critical Reflection. Public Relations Review, 41(2), 170-177. https://doi.org/10.1016/j.pubrev.2014.11.009

Valenzuela, S., Halpern, D., \& Katz, J. E. (2014). Social network sites, marriage well-being and divorce: Survey and state-level evidence from the United States. Computers in Human Behavior, 36, 94-101. https://doi.org/10.1016/j.chb.2014.03.034

van den Eijnden, R. J., Lemmens, J. S., \& Valkenburg, P. M. (2016). The social media disorder scale. Computers in Human Behavior, 61, 478-487. https://doi.org/10.1016/j.chb.2016.03.038

Whisman, M. A. (1999). Marital dissatisfaction and psychiatric disorders: Results from the national comorbidity survey. Journal of Abnormal Psychology, 108(4), 701-706. https://doi.org/10.1037/0021-843X. 108.4.701

Willard, F. H., Jr. (2011). His needs, her needs: Building an affair-proof marriage. Revell.

Woods, H. C., \& Scott, H. (2016). \# Sleepyteens: Social media use in adolescence is associated with poor sleep quality, anxiety, depression and low self-esteem. Journal of Adolescence, 51, 41-49. https://doi. org/10.1016/j.adolescence.2016.05.008

Yen, J. Y., Ko, C. H., Yen, C. F., Chen, S. H., Chung, W. L., \& Chen, C. C. (2008). Psychiatric symptoms in adolescents with Internet addiction: Comparison with substance use. Psychiatry and Clinical Neurosciences, 62(1), 9-16. https://doi.org/10.1111/j.1440-1819.2007.01770.x

Yılmaz, Ö., Boz, H., \& Arslan, A. (2017). Depresyon anksiyete stres ölçeğinin (DASS 21) Türkçe kısa formunun geçerlilik-güvenilirlik çalışması. Finans Ekonomi Ve Sosyal Araştırmalar Dergisi, 2(2), 78-91.

Young, K. S., \& Rogers, R. C. (1998). The relationship between depression and Internet addiction. CyberPsychology \& Behavior, 1(1), 25-28. https://doi.org/10.1089/cpb.1998.1.25

Young, G. K. (2019). Examination of communication and social media usage among socially anxious individuals. [Doctoral dissertation, University of Mississippi]. USA.

Publisher's Note Springer Nature remains neutral with regard to jurisdictional claims in published maps and institutional affiliations. 